\title{
Aportaciones del estudio de la industria lítica a la comprensión del fenómeno calcolítico. Yacimiento de Llanete de los Moros (Montoro, Córdoba) ${ }^{1}$
}

\author{
Carmen GutiérRez Sáez ${ }^{2}$
}

\begin{abstract}
RESUMEN ABSTRACT
Se destaca la abundancia de

This paper wants to remark true fragmentos mesiales de lámina, partidos intencionalmente, $y$ su propuesta como tipo especifico a partir del trabajo de Arméndariz e Iriagaray (1991-92). Se avanza en su importancia como indicador del cambio de concepto durante el Calcolítico frente al utillaje lítico de momentos anteriores.

\section{PALABRAS CLAVE} Industria lítica, soporte laminar,

Calcolítico. outstanding presence of intentionally broken medial parts of black flakes, since Armendariz and Iriagaray (1991-92) proposed them as specific lithic type. It may suggest conceptual changes during Calcholithic times in opposition to eartier lithic implements.

\section{KEY WORDS}

Lithic, industry, blade flakes, Calcholithic.
\end{abstract}

La última quincena de años ha traído un renovado, aunque aún sumario, interés por el estudio de las industrias líticas a partir del Neolítico. En unas fases en que el muestrario de formas se reduce de una manera notable respecto a momentos anteriores, la monotonia de la industria lítica parecía haber perdido el terreno como marcador cronológico ante la cerámica y

' Agradezco a J.C. MARTIN DE LA CRUz la posibilidad de haber realizado el estudio de la industria lítica de este yacimiento y a Q.P. SANZ los excelentes dibujos.

${ }^{2}$ Dpto. de Prehistoria y Arqueología. Universidad Autónoma de Madrid. 
como indicador de procesos económicos frente al metal y otras evidencias arqueológicas. No obstante se van produciendo cada vez más trabajos en nuestro país dedicados a caracterizar amplios conjuntos culturales mediante esta industria, sin descuidar la atención al estudio de tipos específicos 0 al aprovisionamiento de las materias primas y las fuentes de abastecimiento, los talleres. A partir de algunos de los estudios más elaborados se va poniendo de manifiesto la importancia que la industria lítica tiene no solo como marcador cronológico y cultural (Lomba 1995:1103) sino también como indicadora de profundas transformaciones económicas y sociales (Ramos Muñoz 1988-89, Ramos Muñoz y otros 1991-92).

Sin embargo, me gustaría centrar esta reflexión sobre un tema muy concreto dentro del estudio de la industria lítica, el de los soportes laminares y su incidencia en una nueva concepción de la industria lítica desde el Calcolítico. Este tema presenta vertientes complementarias: los soportes laminares dentro de los esquemas de las cadenas operativas de los yacimientos, los indicios funcionales que aportan y la obtención de los recursos líticos.

Para ilustrar estos aspectos me apoyaré en el estudio de los niveles calcolíticos del yacimiento del Llanete de los Moros (Montoro, Córdoba) (Gutiérrez Sáez, en prensa), adelantando que se trata de un estudio tipológico y tecnológico, aunque está previsto ampliarlo con análisis funcionales y de materias primas.

\section{LA INDUSTRIA LÍTICA DE LOS NIVELES CALCOLÍTICOS DE LLANETE DE LOS MOROS}

En este apartado se presenta un cuadro resumen de la industria lítica del total de niveles calcolíticos del yacimiento ${ }^{3}$, en él se indican como datos principales el tipo de soporte, la materia prima y la clasificación tipológica, así como la estructura en que aparece.

Se trata de un conjunto bastante escaso de piezas, 79 , distribuidas en una gran diversidad de fases y estructuras, factor que reduce enormemente la muestra de cada unidad. Se reparten de la siguiente manera:

- Fase I. Estructura I. Silos 1 a 9: 27 piezas.

- Fase II. Niveles IA1 y IA2: 24 piezas.

- Fase III. Interior cabaña (6) y exterior cabaña (22): 28 piezas.

${ }^{3}$ Para una descripción más detallada: GutiérREZ SÁEZ en prensa. 
Aportaciones del estudio de la industria lítica a la comprensión del fenómeno...

Fase I. Calcolítico inicial. Horizonte de silos

\begin{tabular}{|c|c|c|c|}
\hline Silos & M. Prima & Soporte & Tipología \\
\hline $1-1$ & Indet. & plaqueta & fragmento distal de hacha pulida \\
\hline $1-2$ & sílex & frag.mesial de lámina & lámina de dorso con retoque continuo $1 b$ \\
\hline $1-3$ & silex & flanco de núcleo & \\
\hline $1-3$ & sílex & frag.proximal de lámina & lámina con retoque continuo $1 \mathrm{~b}$ y muesca* \\
\hline $1-3 / 5$ & cuarzo & chunk & lasca con retoque continuo $1 \mathrm{~b}$ \\
\hline $\mid-3 / 5$ & silex & frag. distal de lasca & \\
\hline $1-4$ & pizarra? & plaqueta? & hacha pulimentada \\
\hline $1-4$ & sílex & lasca & \\
\hline $1-5$ & silex & frag. distal de lámina & \\
\hline $1-5$ & sílex & frag. mesial de lámina & \\
\hline $1-5$ & silex & frag. mesial de lámina & lámina con retoque continuo $1 \mathrm{~b}$ \\
\hline $1-5$ & silex & lasca & \\
\hline $1-6$ & silex & frag. mesial de lámina & lámina de dorso con retoque continuo $1 \mathrm{~b}$ \\
\hline $1-7$ & arenisca & plaqueta & hacha preformada tallada bifacialmente \\
\hline $1-7$ & indet. & plaqueta & hacha pulimentada \\
\hline $1-7$ & silex & chunk & \\
\hline $1-7$ & silex & chunk & \\
\hline $1-8$ & cuarzo & frag. mesial de lámina & \\
\hline $1-8$ & silex & frag. distal de lámina & taladro \\
\hline $1-8$ & silex & frag. mesial de lámina & \\
\hline $1-8$ & sílex & frag. mesial de lámina & \\
\hline $1-8$ & silex & frag. mesial de lámina & lámina bidenticulada \\
\hline $1-8$ & silex & lasca & \\
\hline $1-8$ & silex & lasca & \\
\hline $1-9$ & sílex & frag. mesial de lámina & \\
\hline $1-9$ & silex & frag. mesial de lámina & $\begin{array}{l}\text { lámina de retoque continuo } 1 \text { b y retoque } \\
\text { bifacial }^{*} 4\end{array}$ \\
\hline $1-9$ & sílex & frag. mesial de lámina & lámina de retoque continuo $2 b^{*}$ \\
\hline
\end{tabular}

Fase II. Calcolítico inicial avanzado. Horizonte de fundación de cabañas

\begin{tabular}{llll}
\hline Niveles & M. Prima & Soporte & Tipología \\
\hline A1 & cuarzo & chunk & \\
IA1 & pizarra & $\begin{array}{l}\text { plaqueta } \\
\text { chunk }\end{array}$ & \\
IA1 & silex & frag. proximal de lámina & \\
IA1 & silex & lámina & punta de base cóncava \\
IA1 & silex & lasca & \\
IA1 & sílex & lasca & azuela preformada tallada unifacialmente \\
IA1 & sílex & plaqueta & \\
IA1 zanja & arenisca & chunk & buril múltiple de ángulo sobre rotura \\
IA1 zanja & cuarzo & chunk & \\
IA1 zanja & cuarzo & chung &
\end{tabular}

\footnotetext{
${ }^{4}$ Las piezas con asterisco indican presencia del llamado lustre de cereal.
} 
Fase II. Calcolítico inicial avanzado. Horizonte de fundación de cabañas (continuación)

\begin{tabular}{|c|c|c|c|}
\hline Niveles & M. Prima & Soporte & Tipologia \\
\hline $\begin{array}{l}\text { AA1 zanja } \\
\mid A 1 \text { zanja } \\
\mid A 1 \text { zanja } \\
\mid A 1 \text { zanja } \\
\mid A 1 \text { zanja } \\
\mid A 1 \text { zanja } \\
\text { IA1 zanja } \\
\text { IA1 zanja } \\
\text { IA1 zanja }\end{array}$ & $\begin{array}{l}\text { pizarra } \\
\text { silex } \\
\text { silex } \\
\text { silex } \\
\text { silex } \\
\text { silex } \\
\text { silex } \\
\text { silex } \\
\text { silex }\end{array}$ & $\begin{array}{l}\text { plaqueta? } \\
\text { chunk } \\
\text { frag. mesial de lámina } \\
\text { frag. mesial de lámina } \\
\text { frag. mesial de lámina } \\
\text { lasca } \\
\text { lasca } \\
\text { lasca } \\
\text { lasca }\end{array}$ & $\begin{array}{l}\text { lámina con retoque continuo } 1 \mathrm{~b} \\
\text { lámina de dorso y retoque continuo } 1 \mathrm{~b}\end{array}$ \\
\hline $\begin{array}{l}\text { IA2 } \\
\text { IA2 } \\
\text { IA2 } \\
\text { IA2 } \\
\text { IA2 }\end{array}$ & $\begin{array}{l}\text { cuarzo } \\
\text { silex } \\
\text { silex } \\
\text { sílex } \\
\text { sílex }\end{array}$ & $\begin{array}{l}\text { chunk } \\
\text { frag. distal de lámina } \\
\text { frag. mesial de lámina } \\
\text { frag. mesial de lámina } \\
\text { lámina }\end{array}$ & $\begin{array}{l}\text { punta retocada } \\
\text { lámina de retoque continuo } 2 b \\
\text { perforador sobre lámina retocada y } \\
\text { truncadura oblicua }\end{array}$ \\
\hline
\end{tabular}

Fase III. Calcolítico pleno. Horizonte de cabañas

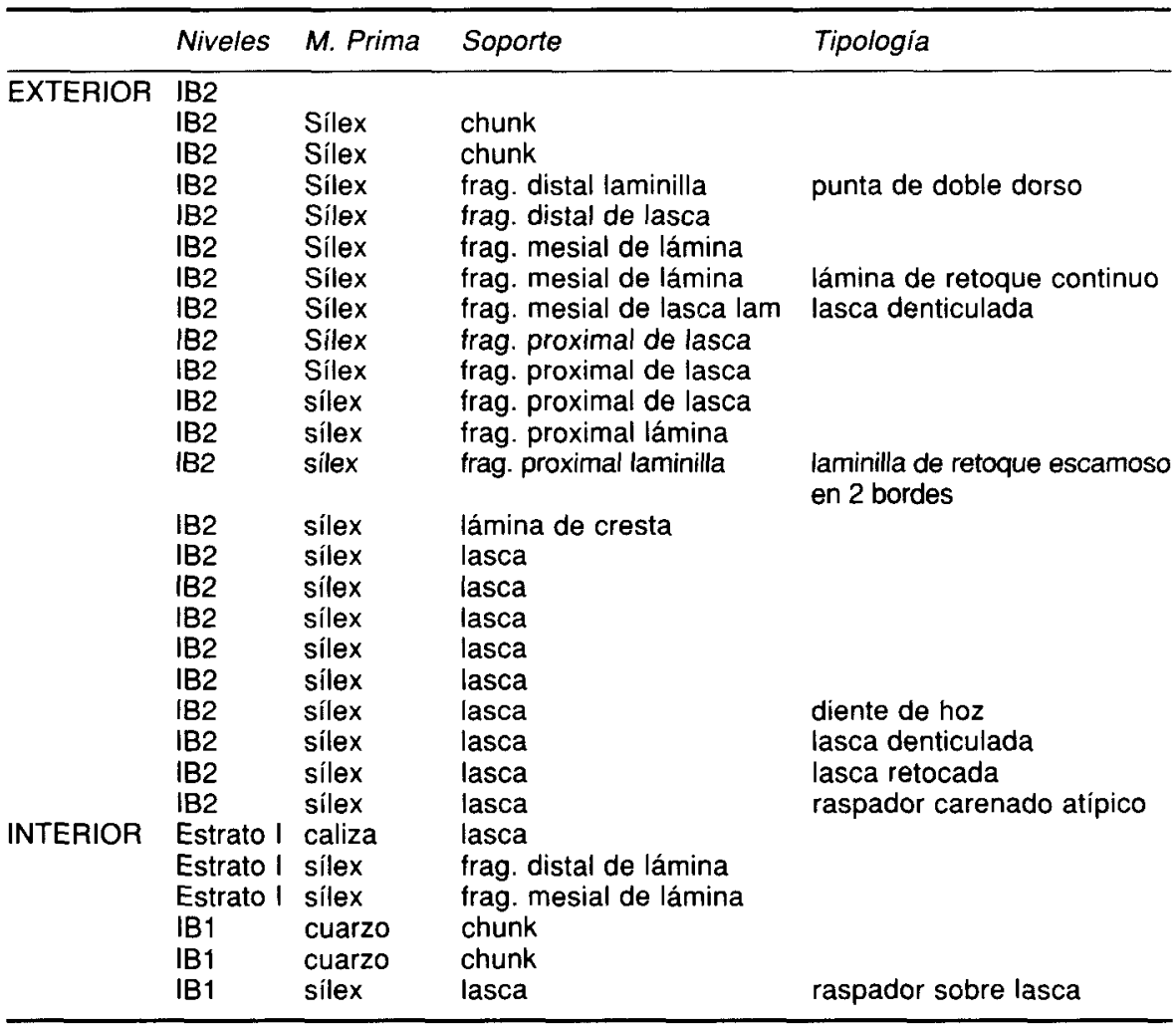




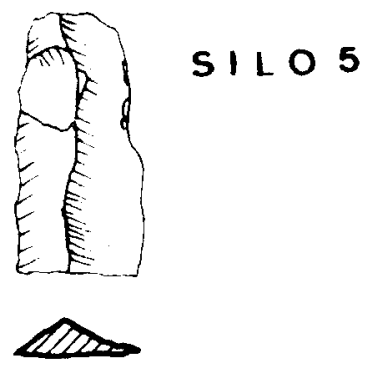

S-4/406E-1

\section{SILO 5}
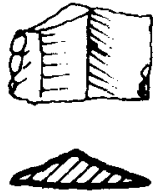

$S-4 / 408 G-1$

SILO 6
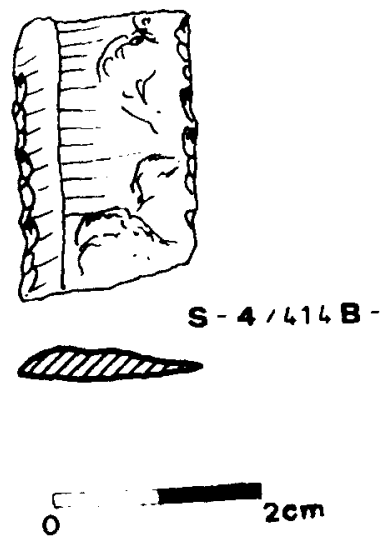

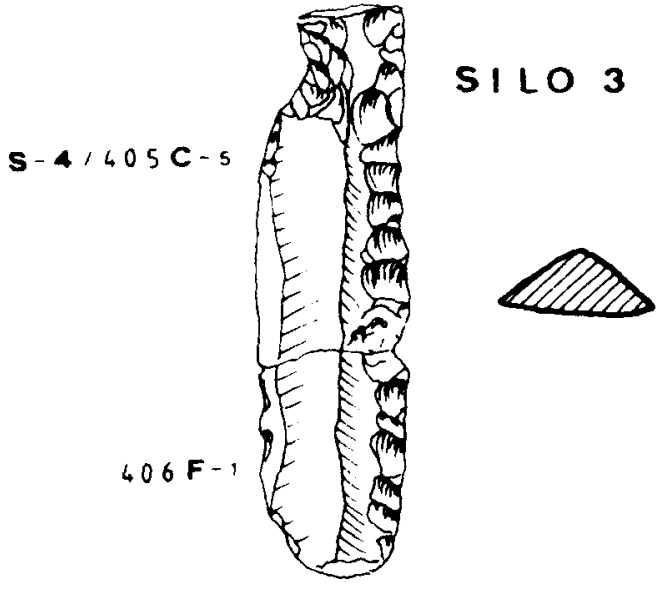

SILO $2 A$
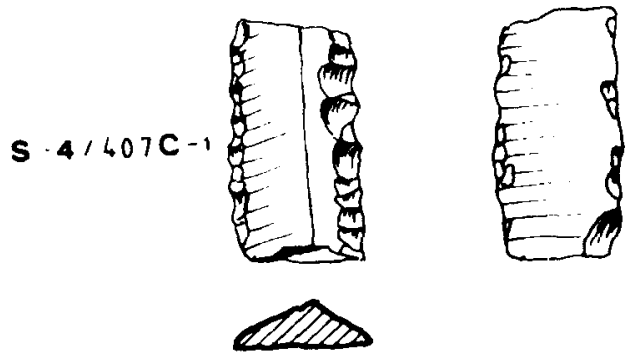

S I LO 5

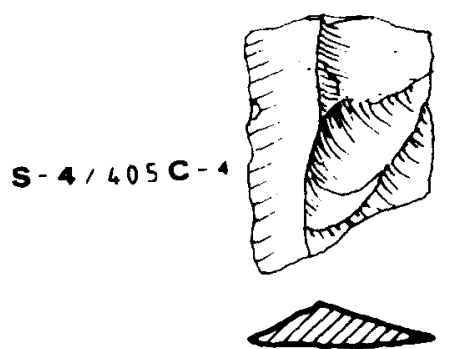

Lámina 1. Fase 1. Horizonte de silos. 

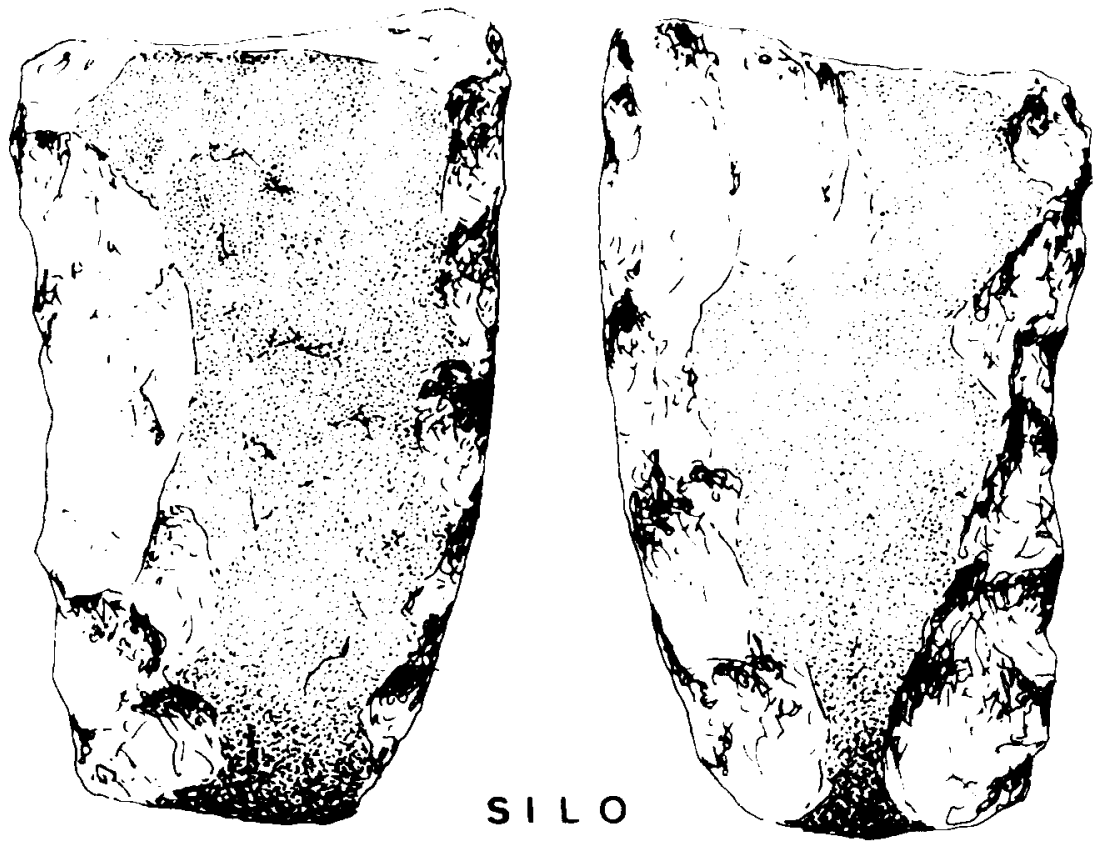

$R-4 / 421 C-1$

SILO

7

SILO 8

SILO 8

SILO 9
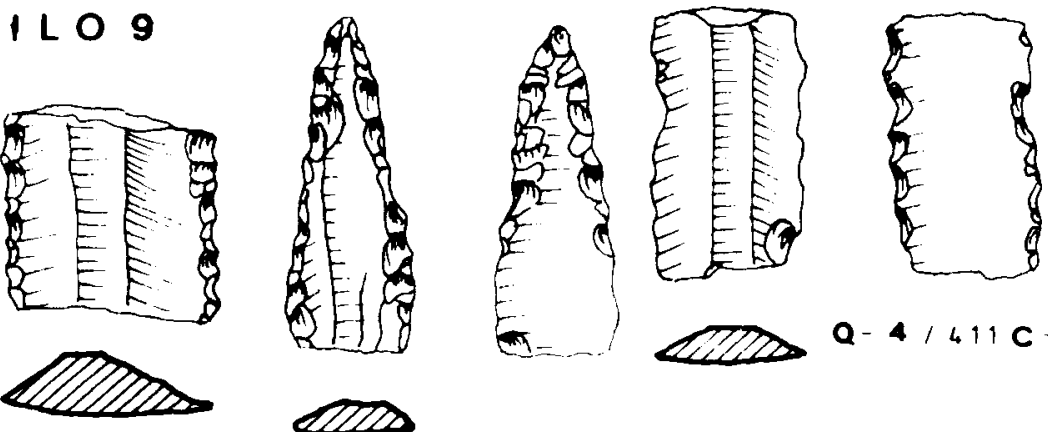

Q $-4 / 412$ C.

$R-2 / 457$ B-1

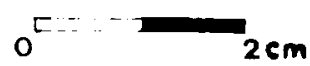

Lámina 2. Fase 1. Horizonte de silos. 


\section{MATERIA PRIMA}

En todos los conjuntos la materia predominante es el sílex, pero no he podido determinar el tipo ni evaluar su calidad en la mayor parte de los casos porque un alto porcentaje de piezas presenta alteraciones como brillo, decoloración y cúpulas térmicas, atributos todos que cuando aparecen conjuntamente indican una exposición al fuego, aunque, de manera aislada pueden deberse también a otras causas. Sobre sílex están hechas todas las piezas retocadas de formato pequeño y, salvo una excepción, los soportes estandarizados, las láminas. Hay que destacar que en la Fase III, en la zona exterior a la cabaña, la única materia recogida es el sílex.

El cuarzo abunda más en la Fase II, sobre él aparece un fragmento mesial de lámina y 7 fragmentos amorfos, hecho que no es extraño pues se trata de una materia difícil de tallar. Otras materias más minoritarias son la pizarra y la arenisca sobre las que se han trabajado una hacha pulimentada y un fragmento apuntado en pizarra; en arenisca se documentan un hacha y una azuela, talladas con grandes extracciones con el fin de dar una forma previa a la materia antes del pulimentado. Finalmente hay una hacha pulida y un fragmento distal de otra sobre materias indeterminadas.

\section{SOPORTE}

Pese a la presencia constante de lascas, fragmentos amorfos e incluso productos de desecho durante el Calcolítico, son los soportes laminares las piezas más significativas cuantitativa y cualitativamente de estos conjuntos en diversas áreas geográficas. En Andalucía las láminas aparecen bien documentadas desde el Neolítico, tanto en hábitats como en talleres y se observa su continuidad durante el Calcolítico en ambos contextos (Ramos Muñoz 1988-89). Sus variaciones parecen deberse, sobre todo, a la anchura, ya que predominan las más estrechas en los momentos de transición al Calcolítico y adquieren una mayor anchura a lo largo de esta fase, fenómeno este también constatado en el País Vasco (Cava 1984).

Este predominio de las láminas revela una clara determinación de obtener una industria homogénea con soportes estandarizados. La técnica empleada parece haber sido la presión y los núcleos, documentados básicamente en los yacimientos-taller, son prismáticos, globuloso-poliédricos $y$ de tallas predeterminadas, todos ellos también presentes desde el Neolítico (Ramos Muñoz et alii 1991-92). 


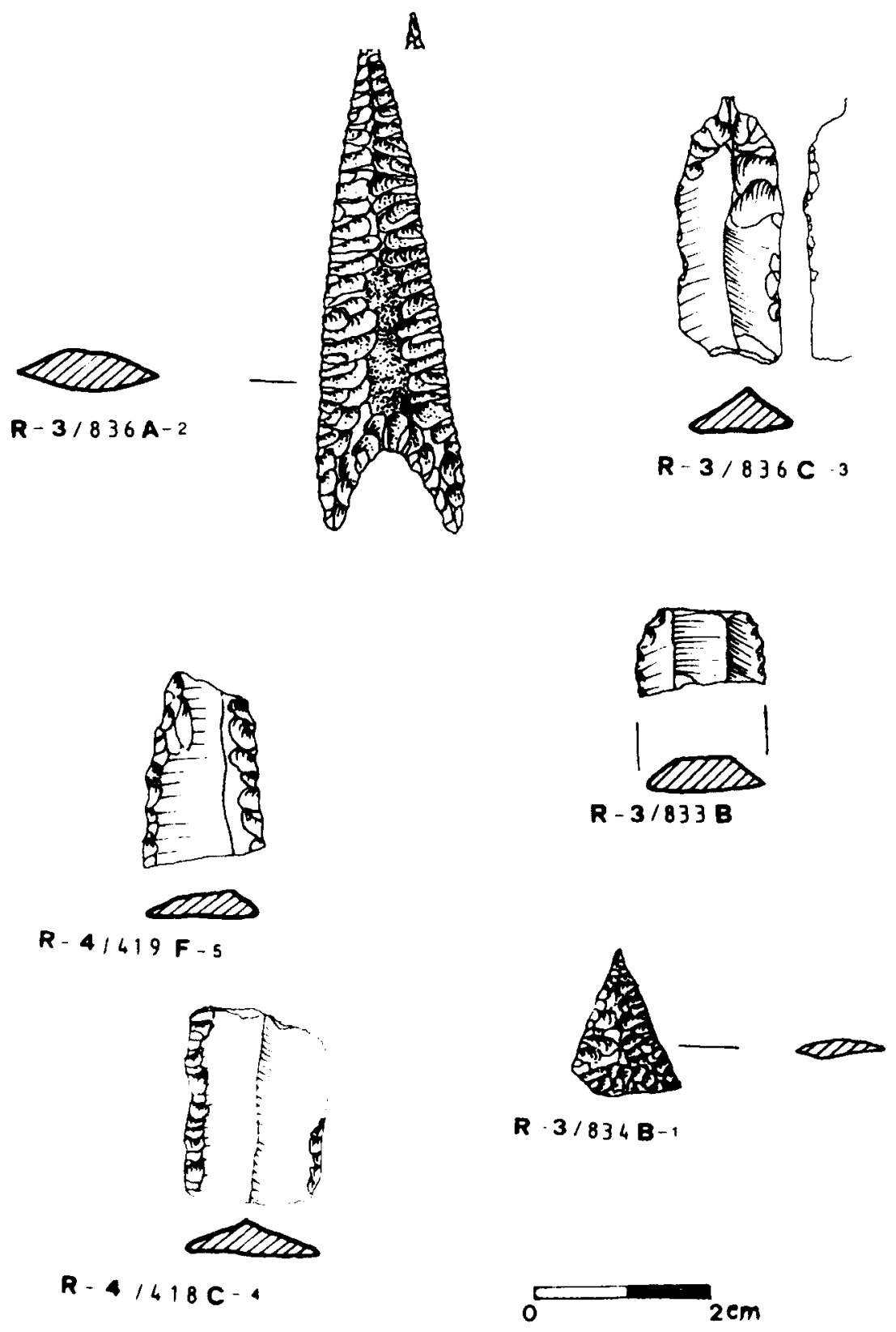

Lámina 3. Fase II. Horizonte de fundación de cabañas. 
Aportaciones del estudio de la industria lítica a la comprensión del fenómeno...

En el estudio de los niveles calcolíticos del Llanete de los Moros llama

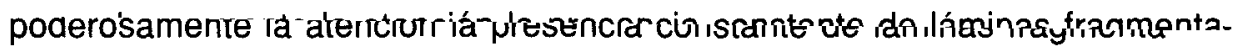
das, hasta el punto de que hay una única lámina prácticamente completa en la Fase II- de un total de 28 soportes laminares en todos los conjuntos, además de una punta de flecha de base cóncava sobre posible lámina.

Distribución y medidas (en $\mathrm{mm}$ ) de los soportes laminares

\begin{tabular}{|c|c|c|c|c|c|c|c|c|c|c|c|}
\hline \multicolumn{4}{|c|}{ FASE I } & \multicolumn{4}{|c|}{ FASE $\|$} & \multicolumn{4}{|c|}{ FASE III } \\
\hline Soporte & L & A & $E$ & Soporte & L & A & $E$ & Soporte & L & A & $E$ \\
\hline Frag. Distal & 26.0 & 14.0 & 4.0 & Lámina & 64.0 & 18.5 & 5.0 & Interior cabaña & & & \\
\hline Frag. Distal & 33.0 & 13.0 & 10.0 & Frag. Distal & 18.0 & 13.0 & 2.5 & & & & \\
\hline Frag. Proximal & 32.0 & 15.0 & 8.0 & Frag. Dista & 32.0 & 13.0 & 5.0 & Frag. Distal & 37.0 & 20.0 & 9.0 \\
\hline Frag. Mesial & 10.0 & 14.0 & 4.0 & Frag. Proximal & 22.5 & 26.5 & 6.0 & Frag. Mesial & 19.0 & 14.0 & 2.5 \\
\hline Frag. Mesial & 14.0 & 13.0 & 6.0 & Frag. Mesial & 10.0 & 15.0 & 5.0 & & & & \\
\hline Frag. Mesial & 20.0 & 16.0 & 3.0 & Frag. Mesial & 16.0 & 16.0 & 4.0 & & & & \\
\hline Frag. Mesial & 20.5 & 20.0 & 6.5 & Frag. Mesial & 16.0 & 15.0 & 4.0 & Exterior cabaña & & & \\
\hline Frag. Mesial & 23.0 & 17.0 & 4.5 & Frag. Mesial & 24.0 & 17.0 & 5.0 & & & & \\
\hline Frag. Mesial & 24.0 & 17.0 & 4.0 & Frag. Mesial & 27.0 & 13.0 & 5.0 & Frag. Proximal & 19.0 & 13.0 & 5.0 \\
\hline Frag. Mesial & 25.0 & 19.0 & 6.0 & & & & & Frag. Mesial & 18.0 & 17.0 & 5.5 \\
\hline Frag. Mesial & 25.5 & 14.0 & 5.0 & & & & & Frag. Mesial & 29.5 & 16.0 & 3.5 \\
\hline Frag. Mesial & 25.5 & 15.0 & 4.0 & & & & & & & & \\
\hline Frag. Mesial & 29.0 & 18.0 & 4.0 & & & & & & & & \\
\hline Frag. Mesial & 29.0 & 19.0 & 5.0 & & & & & & & & \\
\hline
\end{tabular}

No se trata de un hecho accidental sino perfectamente intencionado, ya que sobre algunas de las cornisas entre la cara superior y la fractura se observa una zona deprimida y con escamaciones, característica de un punto de impacto. En la mayoría el plano de fractura es sinuoso y con charnela, tipo que tradicionalmente se ha asociado con la flexión, asi Armendáriz Martija e Irigaray Soto (1991-92) han reproducido esta forma de fractura con las mismas consecuencias. No obstante también pueden obtenerse planos sinuosos y charnelas por percusión aplicando una fuerza excesiva en el impacto (Javier Baena, comunicación personal). Por otra parte, en el conjunto en estudio los fragmentos laminares revelan una cuidada técnica de talla que se deduce por la regularidad de los soportes, con lados paralelos y una o dos aristas también paralelas en la cara dorsal.

Variaciones en las medidas de los soportes

\begin{tabular}{llll}
\hline FASE I & L: $10-29 \mathrm{~mm}$ & A: $13-20 \mathrm{~mm}$ & G: $3-6.5 \mathrm{~mm}$. \\
FASE II & L: $10-27 \mathrm{~mm}$ & A: $13-17 \mathrm{~mm}$ & G: $4-5 \mathrm{~mm}$. \\
FASE III & L: $18-29 \mathrm{~mm}$ & A: $14-17 \mathrm{~mm}$ & G: $2.5-5.5 \mathrm{~mm}$. \\
\hline
\end{tabular}


Las medidas de los soportes obtenidos también son elocuentes en el caso de los fragmentos mesiales. En la Fase I, Calcolítico antiguo inicial, hay mayor variación tanto en la longitud y la anchura como en el grosor, frente a las Fases II y III donde los fragmentos son algo más homogéneos. Parece claro que se ha buscado de una manera intencional unos soportes rectangulares, generalmente más largos que anchos, aunque unos pocos son semejantes o incluso con una anchura ligeramente mayor. Pero este hecho también evidencia una actitud específica: restarle longitud a las piezas, es decir, producir soportes notablemente cortos en relación a la anchura, hecho que, en principio, parece tener poco sentido puesto que es justamente la parte activa del futuro instrumento la que se acorta intencionadamente.

\section{CONFORMACIÓN TIPOLÓGICA}

Exceptuando las hachas y azuelas pulimentadas, que aparecen en distintas materias, sobre sílex se documentan muy pocos instrumentos con una tipología específica y bien definida: dos puntas de flecha ${ }^{5}$, un taladro y un perforador sobre lámina retocada y truncadura oblicua. Sobre lascas: dos raspadores, un denticulado, un diente de hoz ${ }^{6}$ y un buril diedro, además de otro múltiple sobre chunk.

Una buena parte de todo el conjunto laminar aparece con retoques sobre uno o dos bordes. En pocos casos se trata de retoques abruptos que conformen dorsos ( 3 piezas) o bien otras formas ( 1 pieza bidenticulada y 1 muesca).

La mayoría de las piezas retocadas - 13- ofrecen sobre sus bordes un conjunto de retoques que presentan todo tipo de regularidad, tamaño y forma: simples, escamosos, discontinuos, continuos, medianos, muy grandes..., que pueden morder marginalmente el borde activo o conformarlo de manera más drástica. Se han descrito como piezas con retoque continuo. La mayoría de los retoques se sitúan sobre la cara superior y en unos pocos casos mantienen una posición bifacial. En ocasiones van unidos a otras modificaciones como una muesca, un taladro y una truncadura o un dorso, aunque no faltan aquellas piezas con distintos tipos de retoque sobre cada borde.

Inicialmente estas piezas de retoque continuo no parecen ser tipos predeterminados de manera intencional y definida, es decir, que los retoques hayan sido realizados dentro de la secuencia de conformación de un

De una de ellas se conserva solo el fragmento distal.

${ }^{6}$ Con silueta trapezoidal y filo activo opuesto a dorso natural. 


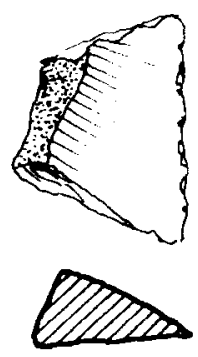

$402 F$

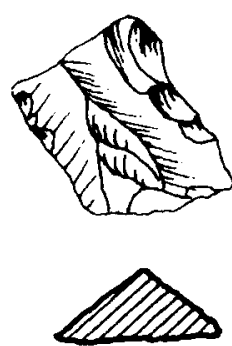

$402 \mathrm{D}$

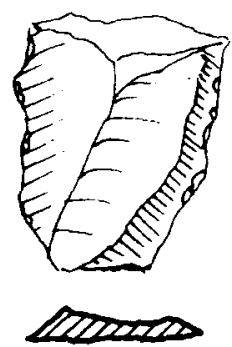

$402 \mathrm{C}$

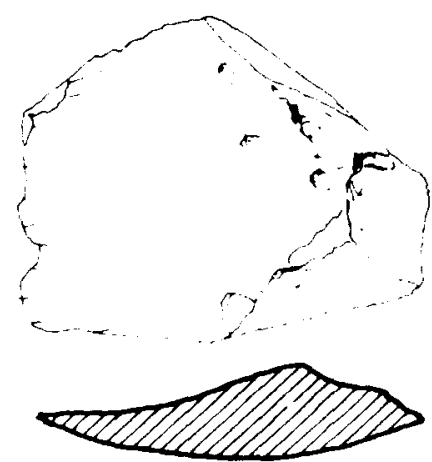

$403 B$

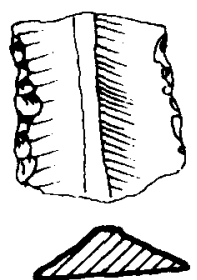

$403 B^{-1}$
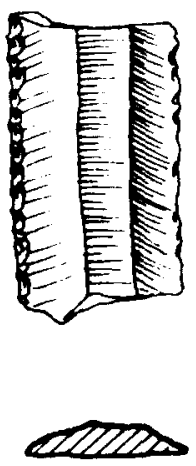

$R-3,833 C-1$
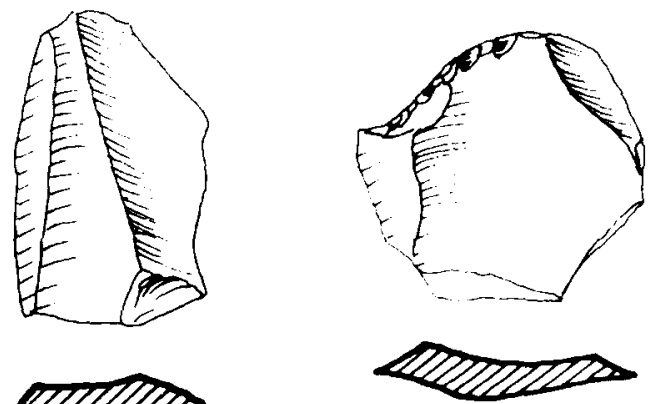

$R-4 / 415 D-1$

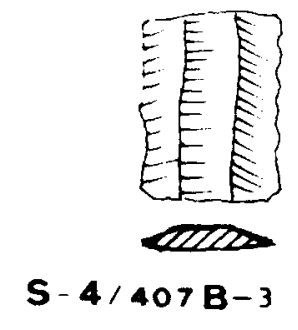

S - 4/407B-3

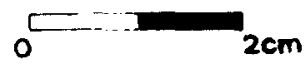

Lámina 4. Fase III. Horizonte de ocupación de cabañas. 
instrumento y previamente al uso. La diversidad de atributos del retoque evidencia una falta de estandarización notable, que es específica además de otra causa: el uso. Cabanilles (1984:55) ha tratado ya este problema discriminando entre utillaje retocado o no. En el primer caso, una línea de retoque vendría definida por series continuas de extracciones, aunque reconoce que su origen puede ser intencional o funcional.

El esquirlamiento o los desconchados de uso suelen definirse frente al retoque por la variedad de formas, tamaño y disposición. Pero en ambos casos su grado de uniformidad viene determinado por la regularidad del esfuerzo, por lo que no siempre es posible conocer la causa, incluso después de un detallado análisis traceológico.

En definitiva, el utillaje, usado o potencial, sobre lámina está formado por un conjunto de soportes mesiales que ofrecen sobre sus bordes distintos estigmas de conformación y/o utilización. Sobre tres de estas piezas hay un lustre de cereal bastante claro, todas ellas pertenecen al nivel de silos. El utillaje sobre lasca se limita a denticulados, raspadores y buriles.

Otro aspecto a tener en cuenta es la distribución de los soportes y piezas retocadas en el yacimiento, que en este caso pudiera ser bastante reveladora.

\section{Fase 1}

La industria lítica ofrece una interesante distribución en dos grupos de estructuras, relacionadas con los tipos/soporte y las alteraciones. Se puede expresar de la siguiente forma:

- Grupo 1. (Estructuras: $1-1,1-4$ y 1-7): en ellas se documentan instrumentos de gran formato - hachas y azuelas, una inacabada - alterados por concreciones.

- Grupo 2. (Estructuras: I-2, I-3, I-5, I-6, I-8, y I-9): soportes laminares retocados -y los lustres funcionales-, lascas, láminas y el flanco de núcleo. Las alteraciones parecen deberse a la presencia del fuego.

- Grupo 3. (Estructura: 1-3/5): un fragmento amorfo con un lado retocado y una lasca; no presentan alteraciones. Este subgrupo pudiera integrarse dentro del anterior ya que estratigraficamente forma parte de él y lo anodino de su industria ni afirma ni desmiente su carácter.

Esta neta distinción entre piezas y alteraciones pudiera ser indicio de una diferente funcionalidad de los denominados silos. ¿Son las estructuras del 
grupo 2 basureros donde se arrojan piezas quemadas y, en consecuencia, inservibles? Y el grupo 1, ¿se trata de áreas de reserva de útiles pesados que es preciso amortizar? Un estudio integrado del contenido total de estos silos y su distribución pudiera arrojar alguna luz sobre estos aspectos.

\section{Fase /l}

Dentro de esta fase destaca la mayor variabilidad en materias primas, soportes y retoques dentro la zanja, lo que apuntaría a un relleno conformado por material de desecho. Las huellas de fuego son también evidentes.

\section{Fase III}

En todo el conjunto la proporción de soportes se altera respecto a las fases anteriores, constatándose aquí más lascas que en el resto. En este momento se han distinguido dos áreas, el interior y el exterior de las cabañas, pero no hay una clara diferenciación entre ambos conjuntos puesto que estamos ante una muestra muy pobre, numérica y tipológicamente; coexisten instrumentos sobre lasca, de factura rápida junto a otros más elaborados en laminas y laminilla. Cabe destacar la mayor incidencia de las alteraciones sobre las lascas, que evidencian un fuego más intenso, sobre todo en la zona exterior de las cabañas.

Aparecen dos fenómenos que pudieran explicar esta diversidad: uno funcional, ya que estamos en áreas distintas y otro cronológico, puesto que las fases también lo son. Las diferencias entrevistas pueden deberse muy bien a la función, pero la pobreza del material de la Fase III pudiera estar relacionada con la expansión del metal que se da en estos momentos, además de con un contexto doméstico.

\section{LOS FRAGMENTOS MESIALES DE LÁMINAS COMO UN TIPO DEFINIDO}

En un trabajo anterior planteaba que, en términos estrictos, habria que dejar de considerar como tipos a estas piezas, aunque no como útiles, puesto que de utillaje se trata en definitiva, bien por la presencia de huellas de uso, bien por la potencialidad del instrumento. Ahora, nuevas perspectivas me inducen a apoyar su vigencia como tipo.

Este mismo fenómeno de los soportes mesiales ha sido constatado por Armendáriz Martija e Irigaray Soto (1991-92) en un estudio de conjuntos 
líticos navarros al aire libre, de cronología postpaleolítica. Los yacimientos se inscribirían en tres fases: Neolítico pleno, Neolítico final a Calcolítico v brofice antıguö y medio. Los autores destacan la dificultad de estimación cronológica y cultural de una buena parte de estos yacimientos al aire libre, en los que no siempre existen cerámicas características $u$ otros fósiles directores; no obstante algunas dataciones obtenidas de excavación les han permitido proponer las fases mencionadas.

El hecho especifico en que ambos investigadores insisten es la presencia de unas piezas que denominan E.H.R.: Elementos sobre hoja recortada, que alcanzan altos porcentajes y aparecen rotos por flexión. Estas piezas presentan una morfología semejante a las del Llanete de los Moros: "soportes de anchura y espesor constantes... de silueta rectangular o cuadrangular obtenida por dos fracturas intencionadas ..." y sus medidas son apenas más homogéneas (L:10-25 mm, A:12-15 mm, G: 5 mm). (1991-92:225).

Hay un rasgo, no obstante, que diferencia ambos casos, la presencia de un retoque abrupto en las piezas navarras -truncadura-, que sirve para eliminar charnelas y convexidades. Entre las piezas cordobesas, sus artesanos no han puesto el mismo interés en regularizar los extremos, ya que no hay ninguna truncadura sobre las fracturadas y sólo una oblicua en la lámina determinada como casi entera ?

En los dos conjuntos, sin embargo, se detecta una mayoría de retoques directos, que en las piezas navarras parecen distinguirse bien de los desconchados de uso. Por el contrario, allí no hay ningún caso de denticulados ni de lustre de cereal.

Aunque Armendáriz e Irigaray proponen inicialmente un nuevo tipo de pieza lítica definida por "la obtención de un fragmento mesial de hoja mediante flexiones sistemáticas y posterior retoque" acaban incluyendo también aquellos fragmentos no retocados, ya que el criterio de distinción sería la flexión, porque "no encontramos elementos en contra de considerar la técnica de fragmentación sistemática por flexión con el mismo valor que el que se otorga al retoque en tipologías tradicionales". Este tipo los subdividen en 12 subtipos conjugando entre si el número de fracturas y de bordes retocados (1991-92: 233).

Como posible funcionalidad apuntan la posibilidad de ser insertados en soportes de materia orgánica, aunque no avanzan el tipo de instrumento.

3 Se trata de una pieza con lustre de cereal en el borde retocado y reutilizada como perforador, ya que los retoques que conforman el perforador cortan el pulimento de uso. 
Me parece muy acertada la propuesta de este nuevo tipo cuyo objetivo es obtener un soporte homogéneo casi rectangular, mediante fractura sistemática de láminas más largas. Pienso que habría que ampliar un poco el espectro que define al tipo, e incluir las fracturas por percusión, puesto que lo interesante es la intencionalidad de la fractura y no la forma de llevarla a cabo. Otro aspecto bastante claro es que este tipo no fue planteado para ser empleado de forma aislada sino insertando varias piezas en un mango.

Según su clasificación las piezas del Llanete de los Moros se distribuirian masivamente entre los tipos $7-1$ borde retocado- y $8-2$ bordes retocados-. Teniendo en cuenta este yacimiento se podrian considerar además de estos criterios una amplia variabilidad en cuanto a retoques, formas definidas y huellas de uso sobre los dos bordes. Probablemente al no ser soportes completos no se les ha prestado la atención que requeririan en otros yacimientos, puesto que en algunos casos ni siquiera entran en los cómputos. El descubrimiento y estudio de este tipo de piezas en otros yacimientos de estas etapas culturales pudiera añadir alguna caracteristica para definir mejor el tipo y observar variaciones sistemáticas.

\section{ALGUNAS PROPUESTAS SOBRE LA FUNCIONALIDAD Y LAS IMPLICACIONES TECNOLÓGICAS DE LOS ELEMENTOS SOBRE HOJA RECORTADA}

Uno de los motivos por los que Armendáriz e Irigaray no avanzan una propuesta funcional más definida es, probablemente, por la total ausencia de lustre de cereal en sus conjuntos. Este queda confirmado en las piezas de Montoro, aunque el número de ellas con un lustre claro se reduce a tres.

El denominado lustre de cereal evidencia un trabajo relativamente intenso de materias vegetales -cereales, cañas, juncos-y otras como cerámica, por lo que no debe relacionarse únicamente con labores agricolas, ya que puede entrar en el dominio de la artesanía y de la construcción. Pero, por otra parte, no todo el trabajo de estas materias deja huellas detectables a simple vista sobre los filos activos. Para ello hace falta un tiempo de acción prolongado, materias vegetales más bien frescas y materias primas específicas, ya que no todas se dejan deformar con la misma facilidad ante el uso (Gutiérrez Sáez 1996). Es probable, por tanto que algunas de estas piezas hayan sido utilizadas bien en labores agricolas 0 artesanales sobre materias vegetales y las huellas solo puedan detectarse con un microscopio de altos aumentos. Pudieran ser, en consecuencia, elementos de hoz, quizá incluso aventuraría que puede tratarse de un tipo 
predecesor de los dientes de hoz en gajo de naranja que abundan a partir del Bronce y se tallan de forma sumaria, pero homogénea, sobre lasca.

La clasificación que propone Ramos Muñoz (1988-89: 137-138) sobre elementos de hoz presenta diversos subtipos, si bien se caracterizan por los bordes denticulados, dorsos y truncaduras. Asocia la aparición del proceso estandarizado de los elementos de hoz a la generalización de la agricultura como sistema de producción durante el Calcolítico.

La conformación de los bordes activos parece en principio más organizada que la expuesta en los otros casos, pero esto no excluye a los Ehr como elemento de hoz. Quizá retocar o denticular un borde previamente al uso no haya sido una costumbre común en todos los grupos y está por demostrar que sea estrictamente necesaria. Algunas de las experimentaciones que se están llevando a cabo en la actualidad, contemplando distintos tipos de hoz y movimientos de siega como deslizar la hoz o golpear los tallos, entre otros factores, seguidas de estudios traceológicos aportarán mucha luz sobre los diversos aspectos de las economias antiguas.

Sin embargo las posibilidades funcionales de los Ehr no tiene porque acabar en su uso como elemento de hoz. Es preciso concebir también que quizá la diversidad de retoques y huellas esté apuntando a la variedad de funciones. Sakakun (1993 a, b y c) señala un fuerte cambio tecnológico entre las transformaciones económicas y sociales que dan paso al Calcolítico de Bulgaria. Durante el Calcolítico hacen su aparición grandes láminas de formato estandarizado que se emplean como filos activos de hoz; junto a ellas aparecen elementos de trillo con tamaños homogéneos, hechos sobre fragmentos mesiales de largas láminas. En ambos se puede encontrar lustre de cereal a simple vista, pero bajo el microscopio se detectan algunas diferencias; por otra parte los elementos de trillo presentan unos bordes fuertemente deformados, a diferencia de las láminas de hoz (1993c: 367). La dualidad hojas/soportes fragmentados comentada más arriba puede deberse a un uso diferencial de este tipo.

La misma investigadora ha comprobado, mediante análisis de huellas de uso, que en este período búlgaro los fragmentos mesiales de láminas se empleaban además como elementos a insertar, a modo de azuelas y cepillos, para el trabajo de la madera (1993a) y enmangadas transversalmente, sobre soportes ligeramente curvados, para limpiar y curtir pieles sobre un soporte duro (1993b). Todas estas transformaciones del instrumental parecen responden a la aparición de un trabajo artesanal y especializado. La diferencia frente a momentos neolíticos anteriores parece cifrarse justamente en la adopción de un nuevo tipo de soporte, las 
grandes láminas estandarizas, posible gracias al acceso a un sílex de mayor calidad.

Se abre así un abanico de posibilidades funcionales: elementos de hoz, ¿elementos de trillo?, tilos activos para otros trabajos artesanales. Pero entonces, ¿dónde están las láminas largas?, ¿son sustituidas por las Ehr en este yacimiento? o, como elementos valiosos y amortizables, ¿están en otras áreas no excavadas?

El elemento que llama poderosamente la atención es la dualidad que parece presentarse entre las largas láminas propias del Calcolítico y estos soportes laminares fracturados sistemáticamente. Puede haber diversas razones, entre las que avanzamos dos a modo de hipótesis. La primera es que estas piezas fracturadas sean propias de zonas donde el abastecimiento de materias primas no asegure soportes de gran longitud, en este caso las láminas obtenidas, más pequeñas, serían rotas para poder obtener un filo más largo y regular uniendo diversos fragmentos y eliminando aquellos que como los talones y el extremo distal presentan mayor irregularidad y grosor. Una segunda razón pudiera estar en que el tipo de hoz o el enmangue de otros instrumentos no fuese recto sino curvo, por lo cual diversas piezas más pequeñas se ajustarían de manera más eficiente a la curvatura que las largas láminas. La introducción de estas hoces o enmangues varios, bastante mejoradas respecto a las rectas, pudiera ser un indicio más de esa intensificación agrícola que apunta Ramos Muñoz, e incluso de mejoras en las actividades artesanales.

Las alternativas funcionales o diversidad de usos posibles con el mismo soporte son, justamente, la gran novedad que parece producirse en estos momentos de intensificación económica. La traceología puede confirmar o desmentir este supuesto también en el caso de Llanete de los Moros.

\section{EL PROBLEMA DE LAS MATERIAS PRIMAS: DUALIDAD DE CALIDADES $Y$ ACCESIBILIDAD}

La determinación de las materias y la localización de sus fuentes es uno de los temas en que más se ha insistido en los últimos años, dada su importancia para valorar aspectos como la movilidad de los grupos, sus áreas de captación y/o distribución, e incluso el controvertido tema de los intercambios. Para las etapas a partir del Neolítico avanzado, con una economía de producción plenamente instalada, Binder y Perles (1990) constatan la doble existencia en los yacimientos de instrumentos sumarios 
sobre materias locales junto a otros con técnica muy depurada, por lo común en materias de zonas muy alejadas.

Es un caso claro de cadenas operativas dobles: uso de recursos locales, generalmente más groseros, para instrumentos inmediatos y poco elaborados frente a utilización de materias de calidad empleadas no únicamente para útiles bien conformados sino, especialmente, sobre soportes más depurados y homogéneos. Esta ambivalencia es común ya desde el Paleolítico superior, donde el empleo de buenas materias primas de zonas alejadas está siendo, cada vez, más constatado. En zonas como el Cantábrico centro-occidental durante el Magdaleniense, la escasez de afloramientos de sílex no impide la presencia de materias extremadamente buenas en un cierto número de ocupaciones, sí bien en cantidades minoritarias en relación a materias primas locales de calidades diversas. Pero este mismo fenómeno, a partir del Neolítico, pone de manifiesto un juego de relaciones diferentes, puesto que la cantidad de materias en circulación aumenta en número y variedad. Esta circulación intensiva de las materias primas de calidad, tanto para producir instrumentos funcionales tallados o pulidos, e incluso objetos como adornos -por ejemplo el caso de la variscita de Can Tintoré- se apoya en la intensificación de la mineria desde el Neolítico. Para Binder y Perles (1990: 260), este hecho significa una ruptura técnica importante respecto a momentos anteriores: la separación de los lugares de extracción de aquellos de producción y utilización. Se trataría, sobre todo, de cambios cualitativos donde las fases de extracción y adquisición de las materias no pertenecerían ya a las cadenas operativas de la producción doméstica y, a menudo, la talla tampoco. Las materias circularían ya directamente como núcleos preparados para una talla laminar, o incluso bajo la forma de soportes estandarizados que son las largas láminas de estos momentos. En opinión de los citados investigadores, este factor torna caduca la propia noción de cadena operativa, al aparecer desligadas unas de otras las diferentes etapas en aquellas materias de procedencia lejana. Los usuarios del instrumental de piedra tendrían a su cargo, únicamente, la producción completa de las cadenas operativas de aquellas materias primas locales, que son por lo común de peor calidad.

Aunque este hecho pueda ser cierto en materias primas y zonas determinadas, está por probar tal distancia - funcional y kilométrica - en todos los casos. En Andalucía, gracias a un intenso esfuerzo en la prospección, son muchos ya los talleres encontrados con presencia de buenas materias primas y tallas de soportes estandarizados. Pero los talleres presentan un fuerte problema de delimitación cronológica. Es común que muchas de las áreas con buenos afloramientos de materias primas sean conocidas y ex- 
plotadas desde antiguo, formándose un auténtico conglomerado donde es posible delimitar por remontado pequeños conjuntos desde el punto de vista tecnológico, pero con difícil atribución cronológica. Un acercamiento al tema debiera de incluir análisis petrológicos que permitiesen establecer una relación sólida con los hábitats (Ramos Millán 1984). Además el estudio de las técnicas de talla y distribución de los elementos de la cadena operativa ayuda a delimitar las formas concretas de adquisición. Ramos Muñoz et alii constatan la distribución de productos desbastados en estos momentos en Cádiz (19991-92: 213).

Otro problema será determinar si se daba una obtención directa por parte del grupo o se trataba con algún agente intermediario. En este segundo caso cabe plantear la existencia de artesanos especializados, lo que, por otra parte, apuntaría a una pérdida generalizada de conocimiento del proceso de la talla laminar y abundaría en esa separación entre artesanos y consumidores. Los mecanismos pudieron ser muy variados, con acceso y talla directa sobre talleres locales y materias primas más bastas y diversidad de actuaciones y circunstancias en el caso de los soportes laminares de calidad.

\section{CONCLUSIONES}

Posiblemente las paulatinas transformaciones que se van desarrollando a lo largo del Calcolítico suponen un profundo cambio en el tratamiento de la industria lítica. Frente a la profusión de tipos y la variabilidad de morfologías individualizados, propia de momentos anteriores, nos encontramos con una homogeneidad de formatos, diversificada a penas por los retoques o estigmas de uso. Pero esta monotonía de soportes no es contraria a la variedad de instrumentos. Si en el Paleolítico se esforzaban tallando piezas diseñadas para trabajar individualmente en actividades concretas. Con la excepción probable de las hojitas y algunos raros geométricos, en el Calcolítico parece abrirse todo un abanico instrumental complejo con diseños variados y adaptados a diversas actividades, cuyos filos activos estarían compuestos por elementos regulares - numerosos o únicos-, fáciles de conformar, y más duraderos al ser intercambiables. Desde este punto de vista el esfuerzo recae ahora en la creación del mango y el formato de los elementos a insertar, evitándose asi su preparación por retoque. Su obtención no debe de resultar especialmente difícil, pero está condicionada a la presencia de buenas materias primas y artesanos cualificados en la talla. Pasamos así del utillaje efectivo, pero laborioso de usar, a la herramienta artesanal más rápida y eficaz, del diseño del filo activo al del instrumento 
normalizado. Sigue existiendo en paralelo, aunque en pequeña medida, una industria residual con útiles de dominio más doméstico - raspadores, buriles - o hiperespecializado - puntas de flecha-.

La industria lítica permite, entonces, detectar algunos de los cambios que la intensificación de la economía de producción va desarrollando durante el Calcolítico, y es un agente activo dentro de este proceso, hasta su sustitución paulatina por el metal. Queda por delante un prometedor campo a la investigación, donde la multiplicidad de circunstancias permitiría evaluar no solo aspectos tecnológicos sino también otros de tipo social y económico entre y dentro de los distintos grupos humanos.

\section{BIBLIOGRAFÍA}

Armendariz Martija, J.; Irigaray Soto, S. (1991-92): Aportación al estudio de los yacimientos líticos postpaleolíticos al aire libre de Navarra. Zephyrus XLIV-XLV, págs. 223-240.

BindeR, D.; PERLES, C. (1990): Stratégies de gestion des outillages lithiques au Néolithique. Paleo 2, págs. 257-268.

Cabanilles, J.J. (1984): El utillaje neolítico en sílex del litoral mediterráneo peninsular. Saguntum 18, págs. 30-102.

CAva, A (1984): La industria lítica en los dólmenes del País Vasco Meridional. Universidad del País Vasco. Vitoria.

GutiérRez SÁEz, C (1996): Traceología. Pautas de análisis experimental. Foro.

GutiérRez SÁez, C (en prensa): La industria lítica del yacimiento de Llanete de los Moros (Montoro, Córdoba). El Calcolítico.

Lomba Maurandi, J. (1995): Las industrias líticas talladas del Eneolítico/Calcolítico de la Región de Murcia: tipologia, distribución y análisis contextual. Tesis Doctorales 903 "636". Universidad de Murcia. ETD Micropublicaciones.

Ramos MILLÁN, A. (1984): La identificación de las fuentes de suministro de un asentamiento prehistórico. El abastecimiento de rocas silíceas de manufacturas talladas. Arqueología Espacial 1, págs. 107-134.

Ramos MuÑoz, J. (1988-89): Las industrias líticas del Neolítico en Andalucía, sus implicacionesespaciales y económicas. Zephyrus XLI-XLII, págs. 113-148.

Ramos Muñoz, J.; Valverde lasanta, M.; Romero Sanchez, J.l.; Almagro Blázquez, A. (199192): La tecnología lítica de la transición del Neolítico a la Edad del Cobre en la zona centrooccidental de Cadiz. Zephyrus XLIV-XLV, págs. 207-221.

SKaKUN, N. (1993a): New implements and specialization of traditional industries in the Eneolithic of Bulgaria. Traces et fonction. Les gestes retrouvés. ERAUL 50. Vol 2, págs. 303-308.

SKAKUN, N. (1993b): New implements and specialization of traditional industries in the Eneolithic of Bulgaria. Traces et fonction. Les gestes retrouvés. ERAUL 50. Vol 2, págs. 211-224.

SkAKUn, N. (1993c): Agricultural implements in Neolithic and eneolithic cultures of Bulgaria. Traces et fonction. Les gestes retrouvés. ERAUL 50. Vol 2, págs. 361-368. 